\title{
Investigation of Dielectric Barriers Discharge Plasma Jets for Bactericidal in Chronic Wounds ${ }^{\dagger}$
}

\section{Pipath PORAMAPIJITWAT ${ }^{1, *}$, Phuthitorn THANA ${ }^{2}$, Dheerawan BOONYAWAN ${ }^{2}$, Keratiya JANPONG ${ }^{1,3}$ and Sureeporn SARAPIROM ${ }^{1,3,4}$}

\author{
${ }^{I}$ Nanoscience and Nanotechnology, Faculty of Science, Maejo University, Chiang Mai 50290, Thailand \\ ${ }^{2}$ Department of Physics and Materials Science, Faculty of Science, Chiang Mai University, \\ Chiang Mai 50200, Thailand \\ ${ }^{3}$ Applied Physics, Faculty of Science, Maejo University, Chiang Mai 50290, Thailand \\ ${ }^{4}$ Thailand Center of Excellence in Physics, Commission on Higher Education, Bangkok 10400, Thailand
}

('Corresponding author’s e-mail: poramapijitwat@yahoo.co.th)

Received: 15 December 2017, Revised: 28 September 2018, Accepted: 20 October 2018

\begin{abstract}
The atmospheric pressure plasma technique has been recognized in health care for disinfection in wounds as well as that it can enhance wound healing and reduce pain in patient without side effects. In this study, Dielectric Barrier Discharge Plasma Jets (DBDJs) were used for bactericidal in vitro as well as the efficiency of bacteria killing were investigated using gram positive bacteria, Staphylococcus Aureus (S. Aureus). The DBDJs plasma used He gas at flow rate at $1 \mathrm{~L} / \mathrm{min}$, pulse repetition rate between 50 to $110 \mathrm{~Hz}$ and exposure time 15 to $60 \mathrm{~s}$ for bactericidal. The studies of DBDJs utilized an Optical Emission Spectroscopy (OES) to identify radical species in the plasma. The results of the OES studies showed in DBDJs plasma $\mathrm{N}_{2}, \mathrm{NO}, \mathrm{He}$ and $\mathrm{OH}$ radical groups were found. These radicals in plasma played an important role in bactericidal, including wound healing. The intensity of radical in plasma depends on the repetition rate applied by the plasma system. After DBDJs plasma exposure, plates were incubated at 37 ${ }^{\circ} \mathrm{C}$. Repetition rate and time of plasma exposure were drastically reduced. With the increase in the repetition rate over $100 \mathrm{~Hz}$ or exposure time up to $60 \mathrm{~s}$ for bactericidal, the reduction of bacteria was increased up to $100 \%$. The large clear zone showed the efficiency of bacteria killed ability of the plasma.
\end{abstract}

Keywords: Atmospheric pressure plasma, dielectric barrier discharge plasma jets, bactericidal, chronic wounds, S. Aureus

\section{Introduction}

Bacteria are prokaryotic micro-organisms which have great adaptability to changing environments. They can cause diseases including chronic wound, meningitis, pneumonia etc. Bacteria are divided into 2 major groups: gram positive and gram negative, based on their cell wall structure. Gram-positive bacteria have a relative thick peptidoglycan cell wall, whereas gram-negative bacteria have a thinner peptidoglycan cell wall and an outer membrane containing lipopolysaccharide and protein [1]. One of the gram-positive bacteria is Staphylococcus Aureus (S. Aureus). S. Aureus can cause a broad variety of infections, ranging from minor infections of the skin to post-operative wound infections. The adaptive power of $S$. Aureus to antibiotics leads to the emergence of Methicillin-Resistant Staphylococcus Aureus (MRSA). MRSA is the most commonly identified chronic wounds [2] that may cause sepsis and deaths. Therefore, alternative techniques to stop the growing bacteria antibiotic resistant are proposed. One of

\footnotetext{
${ }^{\dagger}$ Presented at the $10^{\text {th }}$ International Conference on Plasma Science and Applications 2017: October $10^{\text {th }}-11^{\text {th }}, 2017$
} 
those techniques is Cold Atmospheric Pressure Plasma treatment (CAPP). CAPP was widely studied and reported to have high efficiency to eradicate a wide range of pathogens such as fungi, viruses and bacteria (gram-positive and gram-negative bacteria) including MRSA [2].

The CAPP used in medical field have become a rapidly developing interdisciplinary field that brings a new innovative approach in a broad range of biomedical applications [3]. Atmospheric pressure plasma can be operated at an excitation frequency either in the several tens of kilohertz ac range (or pulsed mode) or in the Radio Frequency (RF) range [4]. It has been shown to inactivate many different animalcules including bacteria, fungus, cancer diseases, proteinaceous matters and genetic DNA [5]. Different designs have been proposed and investigated to utilize CAPP in medical applications. CAPP has to be operated at ambient temperatures and low current without harmful chemicals [6]. It is advisable the basic of physical and chemical properties in plasma including power deposition and consumption, electromagnetic, electrical characteristics, optical emission spectrum, gas temperature and other parameter should be delicately manipulated [7].

\section{Materials and methods}

Samples of $S$. Aureus TISTR 2329 were obtained from Thailand Institute of Scientific and Technological Research (TISTR). The $S$. Aureus bacteria were grown in $5 \mathrm{ml}$ nutrient broth (NB) to obtain a bacterial density of approximately $1 \times 10^{7}$ to $1 \times 10^{8} \mathrm{CFU} / \mathrm{ml}$ at $37{ }^{\circ} \mathrm{C}$ for $24 \mathrm{~h}$. The grown bacteria were then diluted with serial dilution to $10^{-4}$ and spread onto nutrient agar plates (NA). Plasma exposure on $S$. Aureus was carried out using a Dielectric Barrier Discharge Plasma Jets (DBDJs) of Photo Bio Care Co. Ltd, Thailand [8]. Plasma was generated at repetition rate between 50 to $110 \mathrm{~Hz}$, time exposure 15 to $60 \mathrm{~s}$ and flow rate of He gas of 1 1/min. Optical Emission Spectroscopy (OES, Fiber Optic Spectrometer: AvaSpec-2048) was applied to detect radical species in the plasma frame. The high voltage waveform was determined by use a high-voltage probe (Tektronix, P6015A). The plasma power was estimated by Lissajous figure [9], whiles the discharge charge was determined by a HV probe (Hantek, T3100). Following plasma exposure, the bactericidal efficiency was observed using Colony Forming Unit (CFU) method. Data of bactericidal efficiency was statistically interpreted.

\section{Results and discussion}

As seen in Figure 1, the strongest OES spectrum of DBDJs corresponding to $\mathrm{NO}, \mathrm{OH}, \mathrm{N}_{2}$ and $\mathrm{He}$ is found at 297.61, 308.99, 337.54 and $709.54 \mathrm{~nm}$, respectively. The emission spectrum has a broad wavelength ranging from 200 to $900 \mathrm{~nm}$. The NO peaks lying between $200-300 \mathrm{~nm}$ are primarily from the NO A-X $(\gamma)$ in the ultraviolet region. However, their intensity is very low. The $\mathrm{N}_{2} \mathrm{C}-\mathrm{B}\left(2^{\text {nd }}\right.$ positive system at $334.27 \mathrm{~nm})$ and $\mathrm{N}_{2}^{+} \mathrm{B}-\mathrm{X}\left(1^{\text {st }}\right.$ negative system at $\left.406.24 \mathrm{~nm}\right)$ are observed at wavelength ranging from 300 to $450 \mathrm{~nm}$, which could result from the excitation processes; the electron excitation from the ground state $\mathrm{N}_{2}(\mathrm{X} 1 \Sigma \mathrm{g}+)$ and the first metastable state $\mathrm{N}_{2}(\mathrm{~A} 3 \Sigma \mathrm{u}+)$ and pooling reaction [10]. The existence of these molecules implied curative properties of the studied plasma because reactive nitrogen species (RNS), reactive oxygen species (ROS) and reactive oxygen nitrogen species (RONS) were found to play an important role in bactericidal reactions [10].

RNS and ROS have 3 important effects on cells including protein oxidation, lipid peroxidation and oxidation of DNA. Regarding protein oxidation, ROS can fragment protein and protein-protien crosslinkages by inducing oxidation in both amino acid side chains and protein backbones. In lipid peroxidation, RNS/ROS can induce electrostatic force in the cell membrane, which therefore steal electron from the lipids in cell membranes, resulting in cell lysis. With regard to DNA, RNS can induce DNA deamination leading to strand breaks $[11,12]$.

In addition, as seen in Figure 2, intensity of the OES spectra increases with the applied pulse rate. Figure 3 shows variation in OES intensity of NO and OH. It is also found that the intensity of both increases with the applied pulse rate. The increase in OES intensity could result from higher decomposition of the active species at higher pulse rate, indicating bactericidal performance of plasma can be increased by increasing the applied pulse rate. 


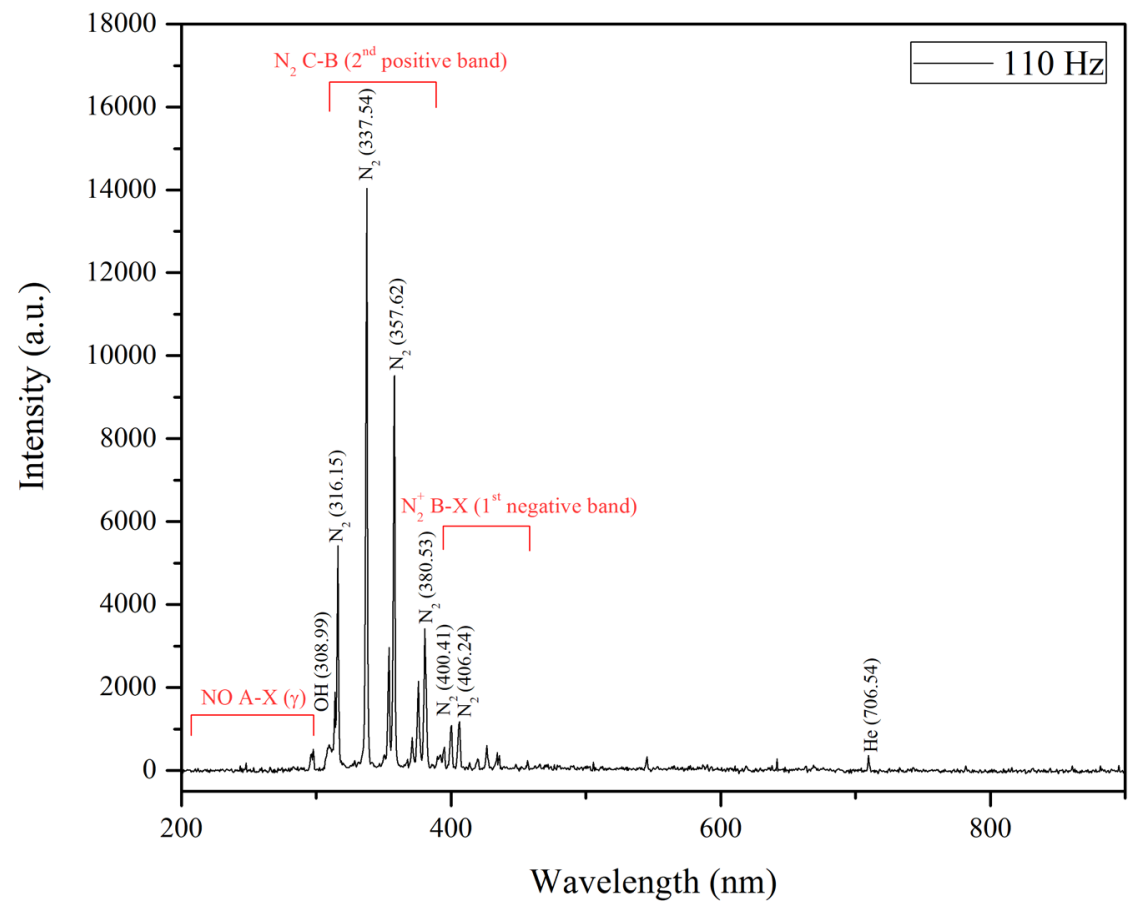

Figure 1 Emission spectra of DBDJs with applied pulse rate at $110 \mathrm{~Hz}$.

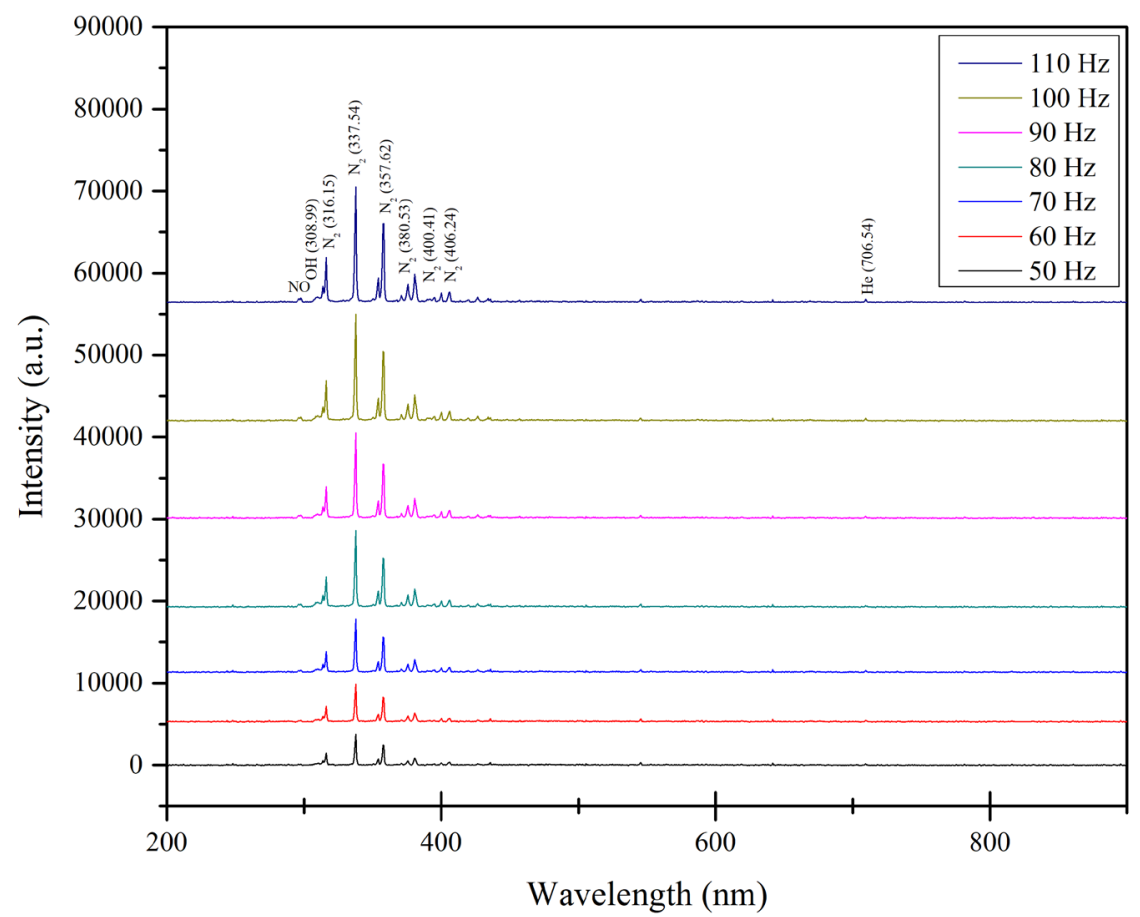

Figure 2 Emission spectra of DBDJs with pulse rate from 50 to $110 \mathrm{~Hz}$. 


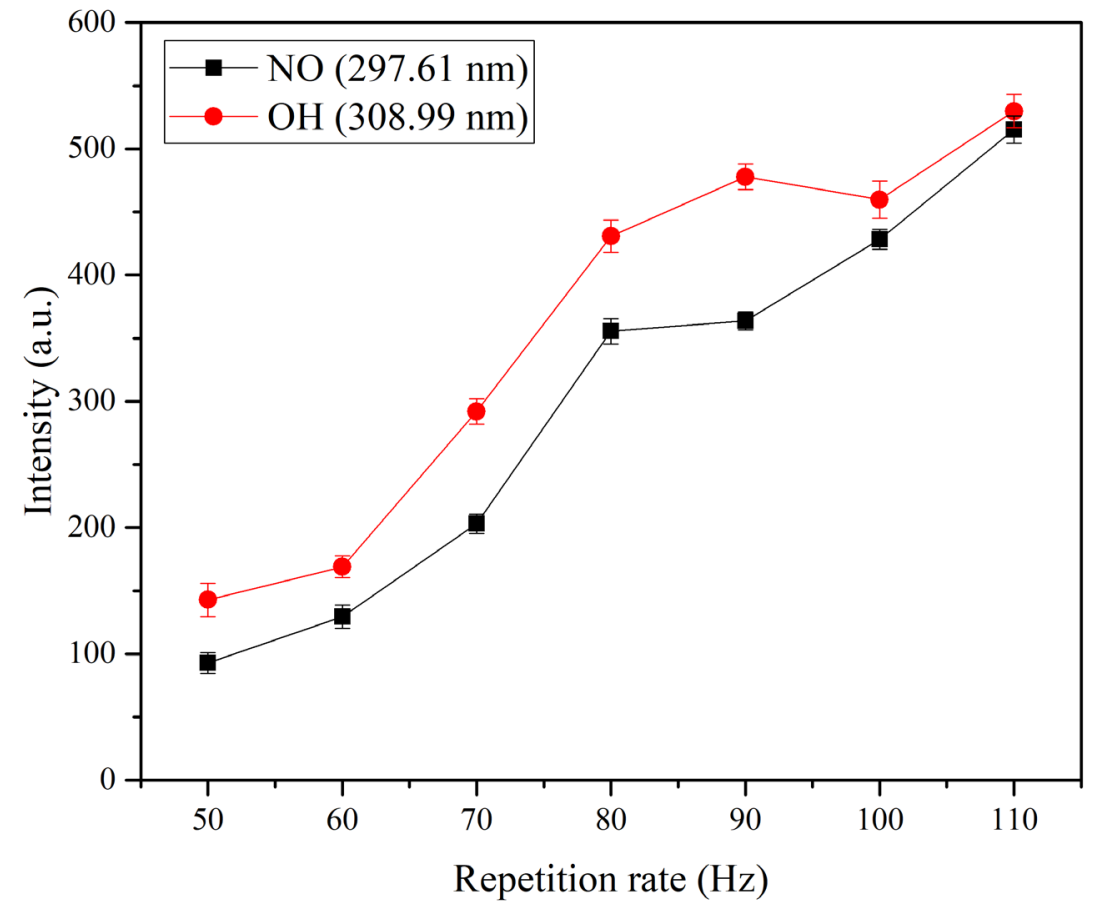

Figure $3 \mathrm{NO}$ and $\mathrm{OH}$ intensity and the applied repetition rate.

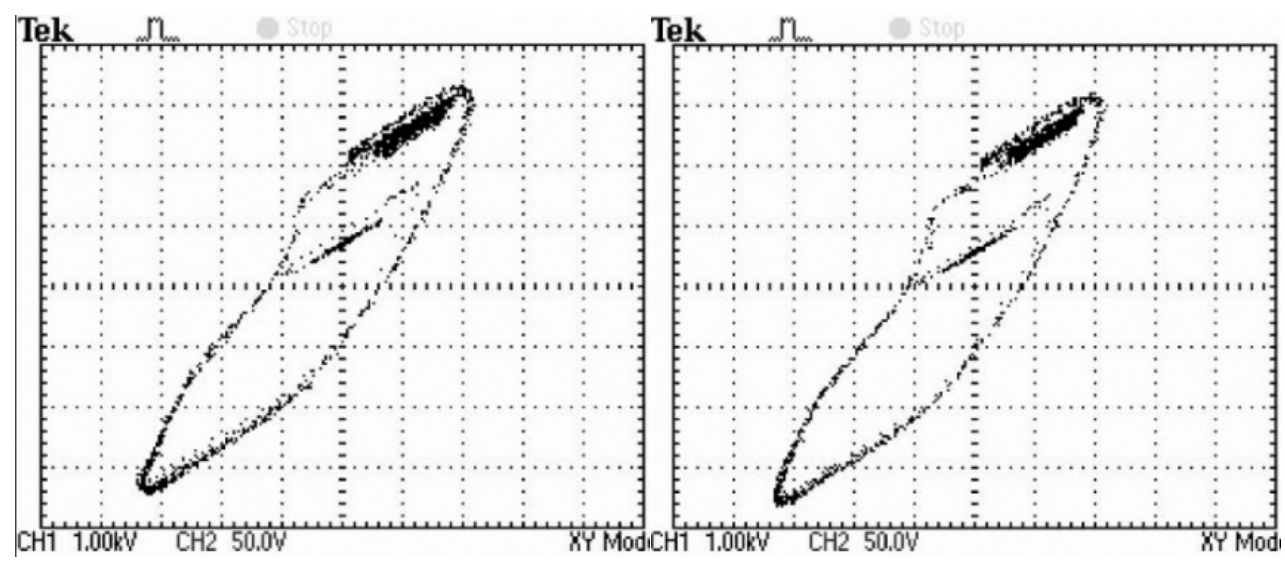

Figure 4 Lissajous figure of DBDJs (a) $50 \mathrm{~Hz}$ repetition rate and (b) $110 \mathrm{~Hz}$ repetition rate.

The Lissajous figure of DBDJs is shown in Figure 4. It is observed that pulse rate at $50 \mathrm{~Hz}$ with duty cycle at 36.7 delivered power of 1.96 watt which was equivalent to dose of $1.17 \mathrm{~J} / \mathrm{cm}^{2}$ [9]. Pulse rate at $110 \mathrm{~Hz}$ with duty cycle at 43.3 delivered power of 2.31 watt that was equivalent to dose of $2.17 \mathrm{~J} / \mathrm{cm}^{2}$. This suggests that increasing the pulse rate and percentage of duty cycle can increase power and dose of DBDJs, which therefore can increase radicals in DBDJs.

Evaluation of antibacterial activity of DBDJs is shown in Figure 5. It is observed that there is no bacteria inhibition zone in Figures $\mathbf{5 a}$ and $\mathbf{5 b}$, indicating that DBDJs with pulse rate at $50 \mathrm{~Hz}$ and time of exposure of 15-30 s does not exhibit bactericidal manner. However, as seen in Figures 5c - 5h, the 
bacteria inhibition zone becomes visible and increases with repetition rate and time of exposure. This reveals that DBDJs were potentially effective in suppressing microbial growth when repetition rate and time of exposure was increased. This finding is consistent with bactericidal efficiency which was evaluated by CFU method (Figure 6). It is seen that bactericidal efficiency increases with both repetition rate and time of exposure. The increase in antibacterial activity demonstrates an increase of antibacterial species generated by excited plasma.
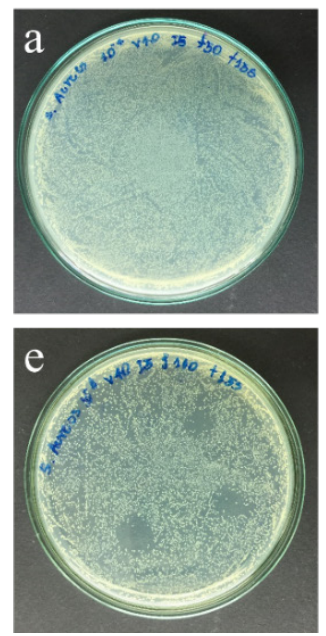
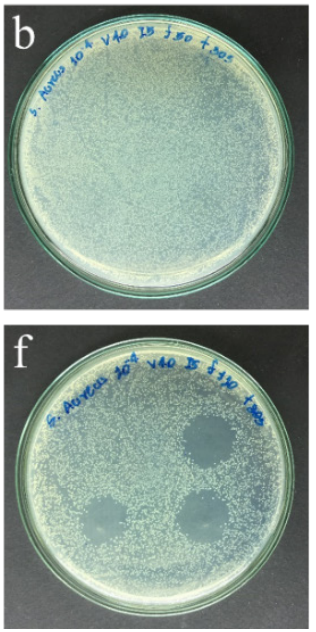
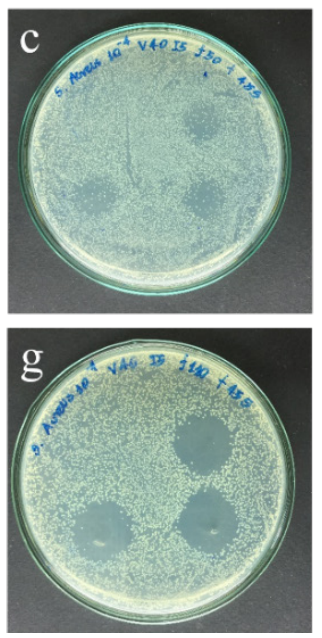
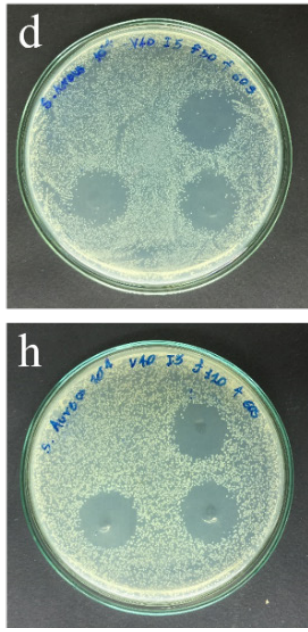

Figure 5 Efficiency of DBDJs to bactericidal (a, b, c and d) at repetition rate $50 \mathrm{~Hz}$ and time of exposure $15-60 \mathrm{~s},(\mathrm{e}, \mathrm{f}, \mathrm{g}$ and $\mathrm{h})$ at repetition rate $110 \mathrm{~Hz}$ and time of exposure $15-60 \mathrm{~s}$.

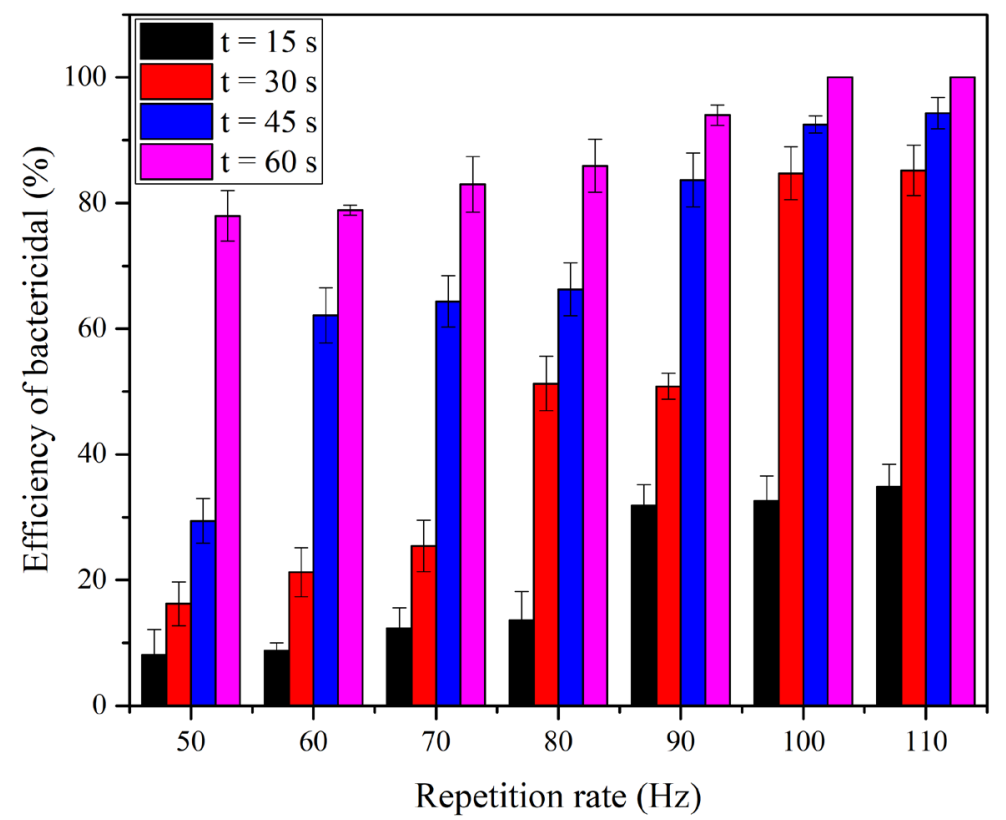

Figure 6 Percentage of bactericidal efficiency. 
http://wjst.wu.ac.th

\section{Conclusions}

The DBDJs generated $\mathrm{NO}, \mathrm{OH}, \mathrm{N}_{2}$ and He species which belong to RONS group and their intensity increased with plasma power. Bactericidal efficiency was dependent on repletion rate and time of exposure: antibacterial activity of the DBDJs increased with dose rate.

\section{Acknowledgements}

We wish to thank C. Kuensaen and C. Yatongchai for research consult, Thailand Center of Excellence in Physics (ThEP) and Graduate School Maejo University for the scholarships. DBDJs has been supported by C. Chutsirimongkol.

\section{References}

[1] ZH Lin, CYT Tschang, KC Liao, CF Su, JS Wu and MT Ho. Ar/O $\mathrm{O}_{2}$ argon-based round atmosphericpressure plasma jet on sterilizing bacteria and endospores. IEEE Trans. Plasma Sci. 2016; 44, 31407.

[2] N Mohd Nasir, BK Lee, SS Yap, KL Thong and SL Yap. Cold plasma inactivation of chronic wound bacteria. Arch. Biochem. Biophys. 2016; 605, 76-85.

[3] EM Kulaga, DJ Jacofsky, C McDonnell and MC Jacofsky. The use of an atmospheric pressure plasma jet to inhibit common wound-related pathogenic strains of bacteria. Plasma Med. 2016; 6, 112.

[4] S Kubinova, K Zaviskova, L Uherkova, V Zablotskii, O Churpita, O Lunov and A Dejneka. Nonthermal air plasma promotes the healing of acute skin wounds in rats. Sci. Rep. 2017; 7, 451-83.

[5] Y Setsuhara. Low-temperature atmospheric-pressure plasma sources for plasma medicine. Arch. Biochem. Biophys. 2016; 605, 3-10.

[6] YW Hung, LT Lee, YC Peng, CT Chang, YK Wong and KC Tung. Effect of a nonthermalatmospheric pressure plasma jet on wound healing: An animal study. J. Chin. Med. Assoc. 2016; 79, $320-8$.

[7] J Heinlin, G Isbary, W Stolz, G Morfill, M Landthaler, T Shimizu, B Steffes, T Nosenko, J Zimmermann and S Karrer. Plasma applications in medicine with a special focus on dermatology. $J$. Eur. Acad. Dermatol. Venereol. 2011; 25, 1-11.

[8] C Yaopromsiri, LD Yu, S Sarapirom, P Thopan and D Boonyawan. Effect of cold atmospheric pressure He-plasma jet on DNA change and mutation. Nucl. Instrum. Meth. Phys. Res. Sect. B 2015; 365, 399-403.

[9] KG Kostov, RY Honda, LMS Alves and ME Kayama. Characteristics of dielectric barrier discharge reactor for material treatment. Braz. J. Phys. 2009; 39, 2322-5.

[10] SJ Kim, TH Chung and SH Bae. Characteristic study of atmospheric pressure microplasma jets with various operating conditions. Thin Solid Films 2009; 517, 4251-4.

[11] SK Kang, HY Kim, GS Yun and JK Lee. Portable microwave air plasma device for wound healing. Plasma Sourc. Sci. Tech. 2015; 24, 1-12.

[12] TV Woedtke, S Reuter, K Masur and KD Weltmann. Plasmas for medicine. Plasma Phys. Rep. 2013; 530, 291-320. 